\title{
Comparison of measuring methods used in compiling topographical maps for linear engineering structures
}

\author{
Vilma Kriaučiūnaitè-Neklejonoviené $\dot{a}^{\mathrm{a}}$ Donatas Rekus ${ }^{\mathrm{a}}$, \\ Vladislovas Česlovas Aksamitauskas ${ }^{\mathrm{b}}$, Andrius Ščepanauskas ${ }^{\mathrm{c}}$ \\ ${ }^{a}$ Kaunas University of technology, Faculty of Civil Engineering and Architecture, Departament of Civil Engineering Technologies, \\ Studentu str. 48, Kaunas 51367, Lithuania \\ ${ }^{\mathrm{b}}$ Vilnius Gediminas Technical University, Department of Geodesy and cadastre, Sauletekio av. 11, Vilnius 10223, Lithuania \\ ${ }^{\mathrm{c}}$ Road and Transport Research Institute, Kanto str. 23, Kaunas 44009, Lithuania
}

\begin{abstract}
Topographical maps are usually made for already existing roads, for their reparation, reconstruction and inventory. The measurements can be made using different measuring methods and a large range of geodetic instruments, from the optical instruments to laser scanning systems. The quality of topographical maps is very important, because roads (streets) are strategic object of a country.The aim of this study was to evaluate the differences between the current measurement methods of producing topographic maps, namely, laser scanning and tachometry. The measuring methods for road and street mapping were analysed and compared, including their technological properties, potentials and efficiency. The results show that the main differences between these methods in composing topographical maps is the measurement and data informativeness, the speed of processing, the level of detail of the results and applicability possibilities.
\end{abstract}

Keywords: topographical syrvey; mobile laserscanning; total station; line engineering construction; road and street mapping.

\section{Introduction}

Linear engineering structures (roads and streets) are considered as strategic objects of the infrastructure of a country. They are relatively narrow and elongated objects of the topographic measurements and are intended for communications. The geodetic activities on the motor roads are an indivisible part of the technological process related to their laying, repair, reconstruction, cadastral measurements or other works that require a precise denotation of the situations within the location. The topographic measurements for roads are performed by means of various measurement methods including various tools, equipment, systems and technologies. At present, the choice of the available equipment is relatively braod, starting from the simplest optical levelling instruments to the laser scanning systems. These instruments make it possible to have automated measurements, solve geodetic tasks, communicate with other devices, process data, immediately present the results, etc. Due to these characteristics, the time of the measurements and cameral works decreases, while the accuracy of the measurements increases. These factors are significant when performing topographic measurements. Fast and accurately performed activities determine the quality of the following constructional works (design, etc.).

The quality and longevity of built highways depend on the quality and accuracy of performed geodetic surveys. The prescribed regulations 'The Engineering Geodetic Analysis of the Motor Roads' [1] determine the general principals, the performance of the geodetic works for the construction of the new roads or roads to be renovated. The regulations present the list of the normative documents, legal acts to be used as the guidelines for engineering geodetic surveys. The set of the documents presents the methodology of the geodetic surveys of roads (streets), however, the indicated documentation is not specified for motor roads. Most of the documents are generic and used when performing the geodetic survey of various objects.

This study presents the assessment of the technological differences between the diverse methods of measurements. The study presents a new approach concerning the topographic measurements on the motor roads (streets) using mobile laser scanning laboratories as an alternative to the traditionally performing measurements. The study visualises and summarises topographic survey results of a linear engineering structure.

Corresponding author: Vladislovas Česlovas Aksamitauskas. E-mail address: ceslovas.aksamitauskas@vgtu.lt

http://dx.doi.org/10.3846/enviro.2014.222

(C) 2014 The Authors. Published by VGTU Press. This is an open-access article distributed under the terms of the Creative Commons Attribution License, which permits unrestricted use, distribution, and reproduction in any medium, provided the original author and source are credited. 


\section{Object ofresearch andMethodology}

In order to evaluate the efficiency and mutual relationship of the methods used for compiling topographic maps, the characteristics of the measuring procedure, the results obtained during the measurements and the possibilities of their adaptability were assessed. The characteristics of the measurements were estimated in terms of time, costs and complexity of the process to attain the results. The data collected and processed during the measurements were analysed by comparing them in between visually and analytically.

The research of the process dealing with the procedure of the topographic map compiling for the experimental linear engineering structure was executed in Kaunas region. The urban and rural environment for the survey was selected not at random. The works and activities were intended to point out the differences of the methods regarding the studied measurements. In Kaunas, there was selected one of the busiest junctures of the traffic flows i.e. the crossroad of Savanoriu Avenue and Taikos Avenue. The distances to be measured comprised $300 \mathrm{~m}$. in Savanoriu Ave. and $150 \mathrm{~m}$. in Taikos Ave. as well as the intersection of Tvirtovès alley (the territory is indicated in Fig. 1). In Kaunas region there was chosen the section of the country road No. 130, Kaunas-Prienai-Alytus, starting from 12.738 to $13.038 \mathrm{~km}$ (300 meters) near Pagiriai village in Garliava county municipality (the territory is indicated in Fig. 2).

The main structural differences of the surveyed objects are the following:

- The intersection of the streets is on the same level with the relief; the section of the road is constructed on the base of the mound, which lifts the road by more than by 4 meters above the naturally prevailing relief when approaching the traffic roundabout.

- The residential 4-5 storied buildings surround the crossroad, the territory is densely developed, but at the same time the structures are missing (with the exception of the road itself) in the rural environment, the meadows are located nearby.

- The traffic roundabout is located across the railway track at the investigated section of the road.

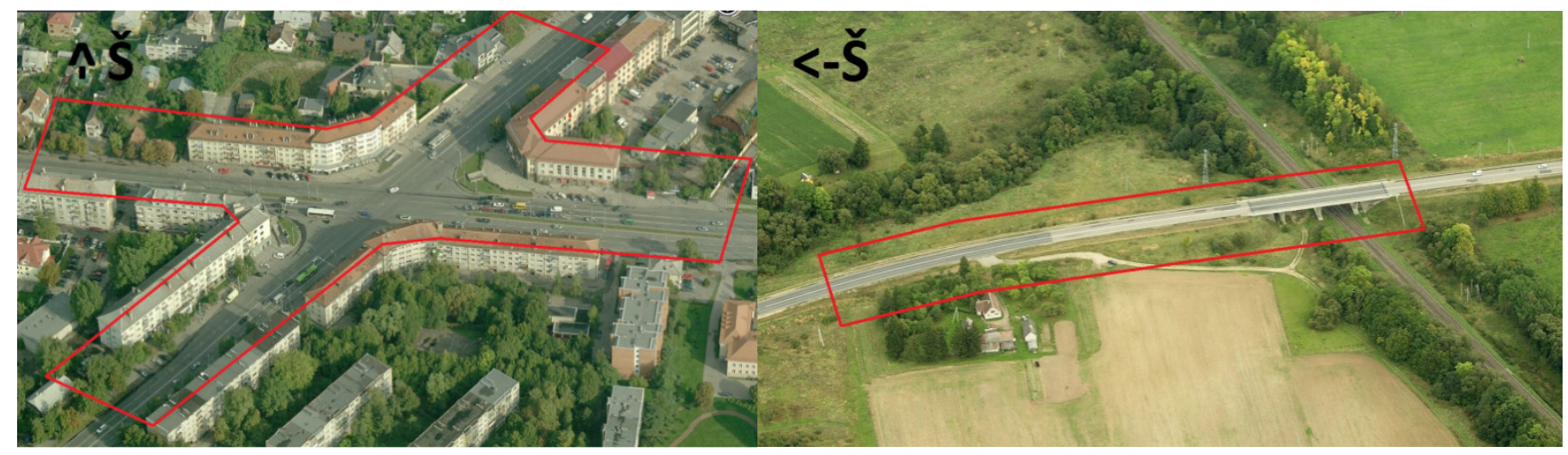

(a)

(b)

Fig. 1. Illustration of the researchobjects: (a) Crossroad of SavanoriųirTaikos str. (b) Section of road No. 130. The red line represents the limits of measurements. (Autor of the schemes is A. Ščepanauskas)

The selected investigated area of the territory was enough to be able to point out the essential differences between the comparative methods. Besides, the size of these territories is close to the scope of the common renovation constructional works of a certain section of a road (street) (a common size of renovated section is $100-500 \mathrm{~m}$ ). The results obtained during the study could assist in selecting the most optimal method of measurement when performing specific works. In both territories, $50 \mathrm{~m}$ wide sections were measured and the area of about 4.25 ha was covered.

\subsection{The applied equipment and measurements}

The works related to the topographic map measurements were performed with the help of the mobile laser scanning system StreetMapper 360 and an electronic tachometer Leica TCRP1205. The portable receiver GNSS Trimble R8 was used for compiling the topographic map background (for collecting the control points).

The mobile laser scanning was performed with the help of the platform of StreetMapper 360 system installed on the body of the terrain vehicle or SUV. The system is based on LIDAR (Light Detection AndRanging) technology, which is used on aircrafts to scan the Earth's surface. The system consists of two high accuracy laser scanners (Reigl), GNSS receiver (Novatel), the module of the inertia navigation system (IGI), two side cameras and computers for storage, inspection and control of the data flows. The system allows the scanning of the infrastructure of roads, the buildings and vegetation recorded directly from the vehicle in motion. Although the system allows carrying out the measurements at various speeds of the vehicle in motion, the scanning of the chosen objects is executed without exceeding the speed limits prescribed for the urban and rural territories, $45 \mathrm{~km} / \mathrm{h}$ and $70 \mathrm{~km} / \mathrm{h}$, respectively.

As the founders of the system [2] indicate, the standard accuracy of the measuring system is less than $2 \mathrm{~cm}$. The system is capable of performing up to $6000003 \mathrm{D}$ measurements per second, which gives the possibility to cover the object to be scanned by a very dense network of points. However, the density of this network depends directly on the speed of driving 
and the configurations of the scanning frequency of the scanners. Namely, the average point density of one scanner within the distance of $5 \mathrm{~m}$ from the scanner, while moving at speed of $60 \mathrm{~km} / \mathrm{h}$ and at the scanning frequency of $300 \mathrm{kHz}$, is 573 points $/ \mathrm{m}^{2}$ [2]. Both scanners are able to view $360^{\circ}$ angle. The maximum technically available distance of the measurement of one scanner due to the $45^{\circ}$ bending angle is up to $300 \mathrm{~m}$.

The field works started when compiling the background points of the map by the mobile GNSS receiver Trimble R8. All the points were collected, using the static method of the measurements, GNSS receiver was held at the point of the base for at least $30 \mathrm{~min}$. The total amount of the collected points for both the objects comprised 11 points of the base. The collected points were marked by the light-reflecting paints, in order to be visible and identified when processing the laser-scanned data.

The mobile laser scanning system was used at the crossroads of Kaunas city with the following maximum scanning frequency of $300 \mathrm{kHz}$, moving forward and backwards at about $45 \mathrm{~km} / \mathrm{h}$ speed in all the directions of traffic. Thus, the full surface coverage by points from all the sides was ensured as well as it enabled to avoid the empty places, which appeared when the vehicles were in motion. When measuring the segment of the road in Kaunas region there was chosen the speed of $70 \mathrm{~km} / \mathrm{h}$ with the maximum scanning frequency, the section was measured forward and backward, therefore, the surface of the points appeared to be slightly scarcer.

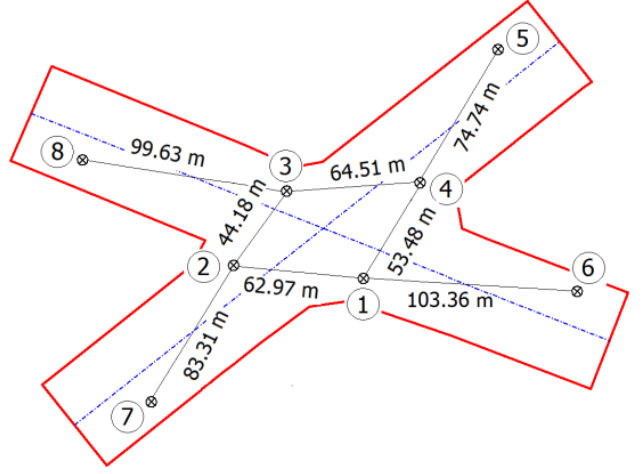

(a)

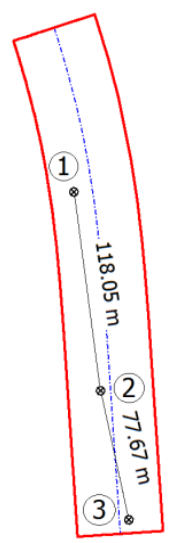

(b)

Fig. 2. Illustration of the picture base points scheme: (a) Crossroad of SavanoriuirTaikos str., (b) Section of road No. 130

When measuring by the electronic tachometer as the base for the map, the network of points collected by GNSS receiver was applied. The measurements in Kaunas city were executed by selecting the stations to be measured at the street corners of the junction, namely at the base points 1, 2, 3, and 4 (Fig. 2a). Such selection of the stations made it possible to view the whole perspective of the target. When performing the measurements in Kaunas region, the tachometer was set up at all the points of the base, by the bridge, close to the bridge and ramps in points 1, 2 and 3 (Fig. 2b), changing the positions twice. The changing of the position was done in order to get a better visibility of the targets located near and under the bridge from both sides. The measurement data were exported using a file format understandable for CAD system and contained information on the codes of the pickets, the planal and altitude position.

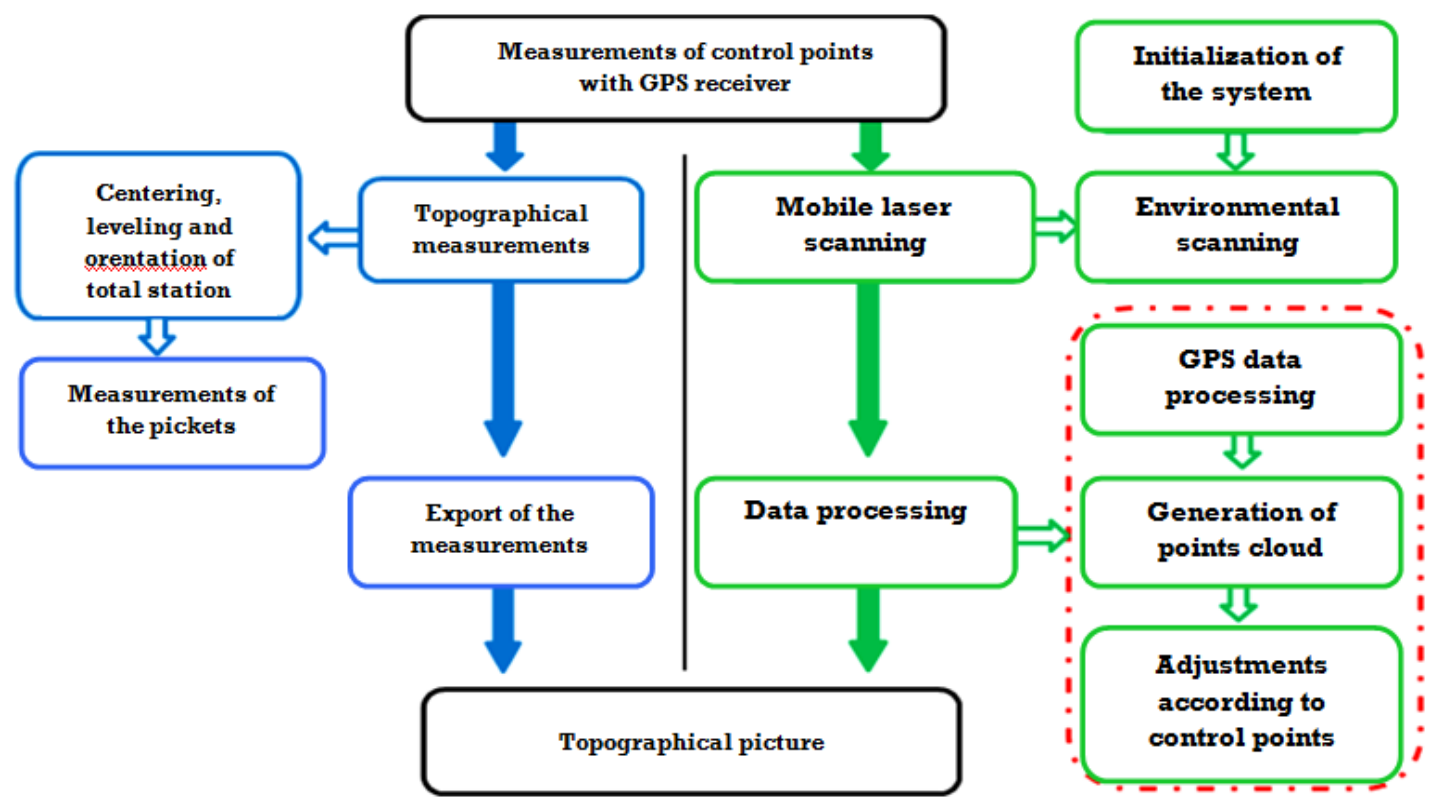

Fig. 3. The workflow of measurements and data processing 
The diagram of the measurements and data (Fig. 3), indicate that each time two steps were performed during the field works. The difference was that the tachometer was relocated several times in both the locations of the objects, every time levelling, centring and polarising the instrument, while using the laser scanning process, the system was initialized only once before commencing the works and measurements were performed continuously. The presentation of the measurement results also differ by three additional steps (in Fig. 3 indicated by a dotted line).

During the process of mobile laser scanning, the collected data were processed with the assistance of four software packages. GrafNav 8.40, was used for GNSS data, AEROoffice V5.3b was used for navigation data, RiWORLD v4.3 was used for generalising the cloud points and Microstation V8i with TerraSolid sub-software programs for managing the points of the cloud (for filtering, for the system of coordinates, application of geoid, etc.) as well as for inspection (erasing of points, editing, etc.). These sub-software programs were used to ensure the inspection of the obtained data and for compensating the required inaccuracies of measurements with the help of the points of the base of the topographic map.

The total number of measurements was made on the first part of the day taking into consideration the most favourable forecasts for locating GPS satellites. In order to avoid distortions of the laser pathway reflection caused by a water film on the measured surfaces, the selected days for measurements had low air humidity, the asphalt and the ground surface was dry, the air temperature was about $+12 \mathrm{C}^{\circ}$.

\section{Results}

The main differences between the methods were identified when analysing the speeds of the data processing, the detailed way of presentation of the results, their accuracy and adaptability, etc. After performing the topographic measurements of the linear engineering object, the general differences and peculiarities of the systems to be compared were defined. The general technological differences of the systems (Table 1) highlighted the advantages and disadvantages of the analysed methods.

Table 1. General differences of technological systems

\begin{tabular}{|c|c|c|c|}
\hline & Comparative object & Mobile laser scanning system & Total station \\
\hline \multirow{6}{*}{ 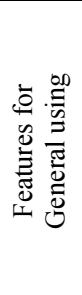 } & Speed of the measurements & High & Low \\
\hline & Results & Point cloud, random distribution of points & Single classified points \\
\hline & Covering of the object with points & $>95 \%$ & $10-20 \%$ \\
\hline & Application & Special instrument & Universal instrument for measurements \\
\hline & Use of the instrument & Simple & Conditionally difficult \\
\hline & Data processing & Complicated & Light \\
\hline \multirow{5}{*}{ 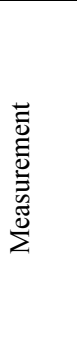 } & Options of the points & $\begin{array}{l}\text { Massifs of the points, individual measurements } \\
\text { are not impossible }\end{array}$ & Only single points \\
\hline & Monitoring of measured objects & $\begin{array}{l}\text { Complicated, on computer screen visible only } \\
\text { readings of laser on objects }\end{array}$ & Objects are visible on straight viewing \\
\hline & Remote control & Impossible & $\begin{array}{l}\text { Possible, when we are using additional } \\
\text { equipment }\end{array}$ \\
\hline & Measurements of invisible points & Impossible & Partially possible, indicating displacements \\
\hline & Work Mode & Full automatic & Manual or half automatic (programming) \\
\hline \multirow{5}{*}{ 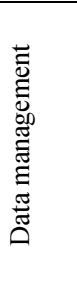 } & Cameral works & Complicated, require considerable manual work & Not necessary \\
\hline & Using of special software & Yes, $>3$ & Yes, $<3$ \\
\hline & Generation of the points & $\begin{array}{l}\text { Slow, depends from computer speed and number } \\
\text { of generation points }\end{array}$ & $\begin{array}{l}\text { Fast, readings file is exported straight from the } \\
\text { instrument }\end{array}$ \\
\hline & "Bad" points & $>10 \%$ & $<10 \%$ \\
\hline & Generation of the points & Automatic and manual & Half automatic \\
\hline \multirow{2}{*}{ 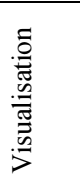 } & Visualisation & Complex structures are shown in details & $\begin{array}{l}\text { Visualized only characteristically collected } \\
\text { points }\end{array}$ \\
\hline & $\begin{array}{l}\text { Consistency with the different media, } \\
\text { overlay of the results }\end{array}$ & Yes & Yes \\
\hline
\end{tabular}

The main and prevailing issues of this study are time input, detailed presentation and accuracy. When analysing the similar studies [3-4] and comparing the accurate 3D methods of measurements (laser scanning, tachometry and photogrammetric), the spent time was evaluated differently. When the planes of a structure floors were investigated by these measurement methods and the measured area was not large [3], the difference between time spent for performing the measurements appeared to be insignificant. Analysing measurement results of the external walls of the medieval castle [4], not a single method could compare to the laser scanning method in terms of the measurement speed. However, it should be 
pointed out that none of the studies indicated the time consumed for the execution of the cameral works, therefore, it remains unclear, what is the general duration of the time (of field works and cameral works) needed to attain the final product.

It is possible to predict the time needed to measure one point by the tachometer (3-6 s). However, it is difficult to estimate the time that the flow of the laser impulses $(600000 \mathrm{imp} / \mathrm{s})$, sent by the scanning system, is going to take to measure one point. It takes different times for every impulse, reflected from various surfaces, to return to the scanners, which is caused by the propertied of surface materials. Furthermore, a part of the laser impulses are not reflected at all, or only very few signals are reflected [5]. Due to these causes, the mathematical calculation of one impulse return to the scanner becomes complicated, thus the calculations of the time duration of measuring one point or their groups becomes unusable.

The time in this study is assessed by evaluating the entire time duration that is needed to measure the whole object. The time consumed for attaining the results or the evaluation of the data was also estimated (Table 2).

Table 2. Comparison of time duration of the measurement methods for measuring linear engineering structures

\begin{tabular}{|c|c|c|c|}
\hline \multicolumn{2}{|c|}{ Tacheometrical method } & \multicolumn{2}{|c|}{ Mobile laser scanning } \\
\hline $\begin{array}{c}\text { Crossroad of Savanoriu and } \\
\text { Taikosstr }\end{array}$ & Section of road No. 130 & $\begin{array}{l}\text { Crossroad of Savanoriu and } \\
\text { Taikosstr (speed } 45 \mathrm{~km} / \mathrm{h} \text { ) }\end{array}$ & $\begin{array}{l}\text { Section of road No. } 130 \\
\quad \text { speed } 70 \mathrm{~km} / \mathrm{h})\end{array}$ \\
\hline \multicolumn{4}{|c|}{ Measurement time (field works) } \\
\hline $2 \mathrm{~h}$ & $30 \mathrm{~min}$ & $30 \mathrm{~min}$ & $20 \mathrm{~min}$ \\
\hline \multicolumn{4}{|c|}{ Measurement processing, generation of the points (cameral works) } \\
\hline $12 \mathrm{~min}$ & $12 \mathrm{~min}$ & $3 \mathrm{~h} 30 \mathrm{~min}$ & $3 \mathrm{~h}$ \\
\hline \multicolumn{4}{|c|}{ General time } \\
\hline $2 \mathrm{~h} 12 \mathrm{~min}$ & $42 \mathrm{~min}$ & $4 \mathrm{~h}$ & $3 \mathrm{~h} 20 \mathrm{~min}$ \\
\hline
\end{tabular}

The measurements made by the scanning system when taking into account its initialization $(10 \mathrm{~min})$, had the duration of 20-30 min for both the analysed targets. It is possible to draw the conclusion from the comparison of the time records of the field works that tachometric measurements directly depend on the number of the measured points, namely the time is wasted when performing the alignment of the separate elements of the situation. During the mobile laser scanner operation, the determining factor of the time input is the size of the object, thus, this method could be more appropriate to measure larger and more complicated targets and objects. During the measurements using tachometer method, the export of collected data lasts for 10-12 min, independently of the scope of the measurements. The handling of the collected data during the mobile laser scanning lasts $\sim 3.5 \mathrm{~h}$. When comparing the time duration of the cameral works, it is obvious that the processing of the laser scanning data is more complicated and requires much time. Summing up the time input for field and cameral works, it becomes obvious that the tachometer method is relatively faster than the mobile laser scanning.

The detailed presentation in this study is defined as a parameter describing the absolute number of the measuring points (readings) on the entire target to be measured per area unit $\left(\mathrm{m}^{2}\right)$. In other words, it is the density of the points. If the conditions are ideal (e.g., when scanning the tunnel), all the laser impulses return to the scanners, then it is possible to measure up to 600 thousand points per second. In cases when the tachometer method is used, only one laser impulse could be sent.Taking into considerationthe similar studies, the laser scanning is the best method regarding the detailed presentation. Zapalkova (2011) stated that it was very important to compile a detailed model of the quarry for its maintenance [6]. It could significantly change the conventional measurements in places where a high level of detail is required during a short period. The results of this study show that during the mobile laser scanning, 34-127 thousand times more points were measured compared with the tachometer measurements (Table 3).

Table 3. Comparison of methods according to the level of detail

\begin{tabular}{|c|c|c|c|}
\hline \multicolumn{2}{|c|}{ Tacheometrical method } & \multicolumn{2}{|c|}{ Mobile laser scanning } \\
\hline Section of road No. 130 & $\begin{array}{c}\text { Crossroad of Savanoriu and } \\
\text { Taikosstr (speed } 45 \mathrm{~km} / \mathrm{h})\end{array}$ & Section of road No. 130 & $\begin{array}{l}\text { Crossroad of Savanoriu and } \\
\text { Taikosstr (speed } 45 \mathrm{~km} / \mathrm{h})\end{array}$ \\
\hline \multicolumn{4}{|c|}{ General number of the points } \\
\hline 468 & 195 & $59.7 \mathrm{mln}$ & $6.7 \mathrm{mln}$ \\
\hline \multicolumn{4}{|c|}{ Averagedensityof the pointsin $1 \mathrm{~m}^{2}$} \\
\hline$<1\left(1\right.$ point $\left./ 59 \mathrm{~m}^{2}\right)$ & $<1\left(1\right.$ point $\left./ 77 \mathrm{~m}^{2}\right)$ & $>2550$ & $>1130$ \\
\hline
\end{tabular}

The matrix of the points received by the scanning system is very dense (the distance between the points is from $1 \mathrm{~cm}$ ) as all the adjacent objects are 'dotted' by points, while during the tachometric measurement only the characteristic points are marked. Such a large detailed presentation, or the excess of points, when compiling the usual topographic plans of the roads or certain engineering studies is not required. On the other hand, the abundance of the information permits a more extensive use of the topographic material. Based on the results of this study (Table 3), a rather different detailed presentation of the street or road was obtained when measuring with the studied methods. The differences are determined by the abundance of the elements of the situation. During the scanning process, the surface is not covered by points or is covered irregularly in cases when the surface does not reflect the laser ray back into the scanner, or the ray is bent irregularly when reflected from the surface. Due to this reason, 'bad' points or their groups appear that do not correspond to the present situation i.e., the points do not belong to any surface. This is valid also for the tachometric measurements using a prism. 
In total, 78393366 points were collected during the study by applying both methods, the number of bad points was 11988114 . The greatest part of the inadequate points was acquired by laser scanning. To clear the inadequate points, TerraScan sub-software filters were used. These calculations are based on the algorithmic calculations, which can be corrected by the user if needed. Meanwhile, the errors appearing during the tachometric measurement process are eliminated manually, because the number of 'bad' points is comparatively low and there is no need to produce complicated filters.

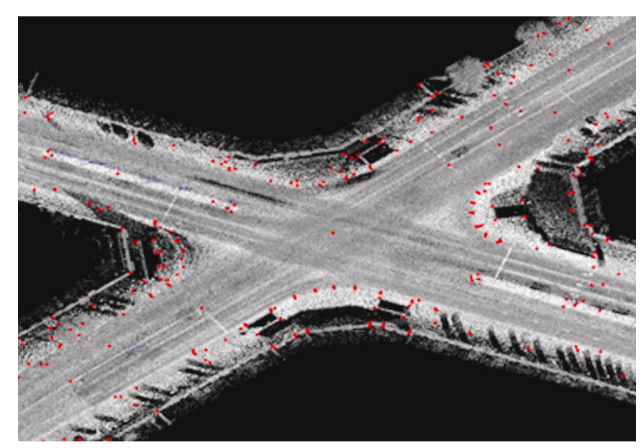

Fig. 4. Measurement results overlay in street intersection (fragment), red points marks tacheometrical traverses

After executing all the necessary procedures of points correction there was estimated the accuracy of the methods. The accuracy was estimated taking into account the differences regarding the altitudes and planned fixation of the target. When evaluating the inter-reciprocal differences of the altitudes of the methods of measurements, the analysis was based on the research methodology suggested by A. Kalantaiteand D. Šlikas [7-8]. Those Lithuanian authors carried out the study and the accuracy of the LIDAR data concerning the altitude were estimated comparing the random points of the topographic plan, collected by using the ordinary methods of measurements, with the most closely set points of the scanned surface. There were selected by a random order 15 points on the hard (stable) and soft (variable)surfaces at the crossroad of the streets. The same number of points was selected in the section of the road. The separate points located on the structurally even surfaces were grouped into 4 groups, namely the herbs, ground, asphalt and concrete coating. The research indicated that accuracy of the altitude points of the scanned surface depends on the materiality of the reflected surface. The attained results (Table 4) allow to make the assumption that the greatest inter-reciprocal coincidence of the methods (accuracy), is achieved on the hard asphalt surface and concrete surface, the worst $(\sim 5 \mathrm{~cm})$ when the laser is used for measuring the herbal vegetation (especially high, dense, not mowed). According the results of the performed analysis (altitude differences)it is possible to state that the accuracy of the measurements is directly dependant on the material of the reflected surface, structure and stability.

After overlapping the results of the measurements received by both methods, an informative data are obtained (Fig. 5). Furthermore, the methods complement each other. For example, during the scanning of the road section at the traffic roundabout, very few data were obtained because the field of the laser scanning was limited by the structures of the bridge. The lack of information at that place could be successfully supplemented by the tachometric measurements. The collection of scanning data at crossroads is more complicated in the areas that are blocked by parked cars where the shadow effect appears.

Table 4. General differences of the technological systems

\begin{tabular}{|c|c|c|c|c|}
\hline & & \multirow{2}{*}{$\begin{array}{l}\text { The number of selected points } \\
\text { (sum; in crossroad; in road) }\end{array}$} & \multicolumn{2}{|c|}{ Average differences of the altitudes, $\mathrm{cm}$} \\
\hline \multicolumn{2}{|c|}{ Dislocation of the points } & & Crossroad of Savanoriu and Taikos str & Section of road No. 130 \\
\hline \multirow{2}{*}{ Soft surfaces } & grasses & $24 ; 13 ; 11$ & 2 & 3.5 \\
\hline & ground & $6 ; 2 ; 4$ & 0.7 & 0.8 \\
\hline \multirow{2}{*}{ Hard surfaces } & road cover & $18 ; 9 ; 11$ & 0.4 & 0.5 \\
\hline & concrete (tiles) & $12 ; 6 ; 4$ & 0.6 & 0.6 \\
\hline
\end{tabular}

The important factor of the planned accuracy is that the operator, while making the alignment of the tachometer, selects the elements of the situation (or their parts) to be measured and the accuracy of the coordination of the particular point depends on the operator's approach and skills. During the laser scanning, all surfaces located in the visible field of observation are covered by a dense network of points. The dense covering of the surfaces rather accurately reflects all the scanned contours and lines, therefore the planned accuracy is determined only by the distance between the lattice points and the error of the scanner range. In this study, the shortest distance between the scanned points was $0.1 \mathrm{~cm}$. The previously applied methodology is not suitable for evaluation of the planned accuracy, therefore the evaluation is suggested to be done in a constructive rational manner, i.e. taking into consideration the measurements of the individual typical elements (Fig. 5).

When measuring the angle, the attained accuracy of both measurements at that location was excellent. When analysing the characteristics of the measurements of a pole (or any other circular or semi-circular element) it was noticed that only one side of the pole was measured by the tachometer (the diameter of the pole was $0.35 \mathrm{~m}$ ), but at the same time the scanner indicated the fully circular element. When measuring this type of targets by the tachometer, their planned position has an 
error of $1 / 2$ of the diameter of the circular element. When evaluating the previous measuring results [9], the contact lines and the electric transmission lines during the laser scanning procedure were represented more extensively and accurately then when measuring by the tachometer.
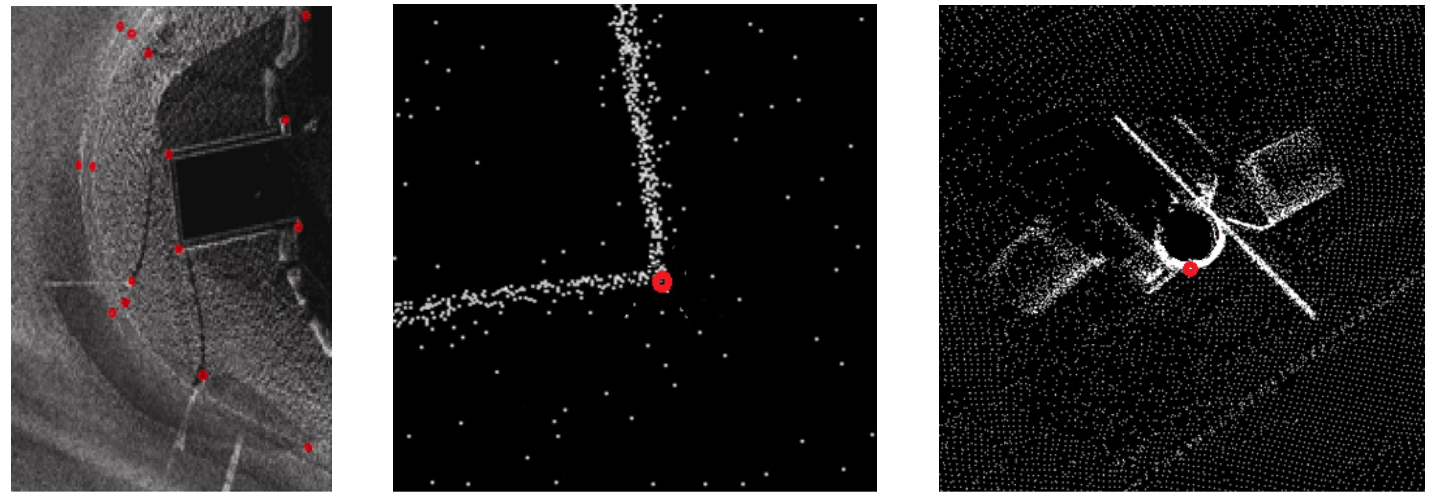

Fig. 5. Data of laser scanning and tacheometrical measurements: typical elements (Crossroad)

Based on the results it is possible to state that both investigated methods are suitable for generation of representative topographic maps and satisfy accuracy requirements for the geodetic survey of roads and streets. Furthermore, both methods fully satisfy the requirements when solving various engineering, geodetic and other tasks. Different level of their detailed presentation enables the solution of the specified tasks beyond for roads and streets. The tachometric method of measurement is more common worldwide and used more frequently than the laser scanning method.

\section{Conclusion}

- After assessing two measuring methods, laser scanning and tachometry, used for the linear engineering structure mapping in terms of their technological characteristics, possibilities for implementation and efficiency, it can be concluded that the main differences between the two methods is the measurement and data informativeness, the speed of processing, the level of detail of the results and applicability possibilities. Both methods can be efficiently used when solving various engineering, geodetic and other tasks.

- The applied laser scanning methods on the same territory within comparatively short period of time ( $\sim 30$ min) allow obtaining a more detailed and informative data $\left(>1000\right.$ points to $\left.1 \mathrm{~m}^{2}\right)$ if compared to the measuring by an electronic tachometer. To measure the targets possessing quite a large and a greater number of elements of situations, it is advisable to apply laser scanning. When the object getslarger, the difference in the time input for the object between the investigated methods becomes smaller.

- Because the attained data are more informative, the system of laser scanning could be implemented for the multiple practical usages. The system is used in the geodetic surveys of the linear engineering structures, for compiling detailed surface models, determining the defects of the coatings, for archaeological, architectural, heritage preservation studies, for engineering and inspection works, contours of water bodies, analysis of the slope stability, etc. The system is able to completely substitute the traditional types of measurements by electronic tachometers. The laser scanning method is also more acceptable in terms of the safety of field works on the roads.

- The choice of the most appropriate method has to be estimated according to four criteria: the scope of measurements, the demand for a detailed presentation, the purpose of the implementation and economic factor. The price and cost effectiveness of the software and the equipment are the most frequent factors determining the prioritized choice of the method.

\section{References}

[1] Statybos taisykles ST 8871063.03:2003. Automobiliu keliu inžineriniai geodeziniai tyrinéjimai. Lietuvos automobilių kelių direkcija.Vilnius, 2003 , 2-3.

[2] Street mapper 360 Specifications [online] [cited 12 March 2013]. Available from Internet: http://www.igi.eu/sm-360.html

[3] Nuikka, M.; Rönnholm, P.; Kaartinen, H.; et al. 2008. Comparison of three accurate 3d measurement methods for evaluating as-built floor flatness, The International Archives of the Photogrammetry, Remote Sensing and Spatial Information Sciences 37(B5): 129-134.

[4] Grussenmeyer, P.; Landes, T.; Voegtle, T.; Ringle, K. 2008. Comparison methods of terrestrial laser scanning, photogrammetry and tacheometry data for recording of cultural heritage buildings, The International Archives of the Photogrammetry, Remote Sensing and Spatial Information Sciences 37(B5): 213-218.

[5] Žalnierukas, A.; Ruzgienè, B.; Kalantaitè, A.; Valaitienè, R. 2009. Miestu skenavimo LiDAR metodu tikslumo analizè, Geodezija ir kartografija [Geodesy and Cartography] 35(2): 55-60. http://dx.doi.org/10.3846/1392-1541.2009.35.55-60

[6] Zapalkova, P.; Smitka, V.; Mikolas, V. 2011. Comparison of tacheometry and laser scanning methods for measuring the quarry in jakubčovicenadodrou, GeoScience Engineering 57(3): 73-88. ISSN 1802-5420.

[7] Kalantaite, A.; Paršeliūnas, E. K.; Romanovas, D.; Šlikas, D. 2012. Generating the open space 3D model based on LiDAR data, Geodesy and Cartography 38(4): 152-156. http://dx.doi.org/10.3846/20296991.2012.758438

[8] Šlikas, D.; Kalantaitè, A. 2013. Vietovès trimačių modelių generavimas taikant erdvinius skenavimo duomenis, Aviacijos technologijos [Aviation Tehcnologies] 1(1): 52-56.

[9] Kremer, J.; Hunter, G. 2007. Performance of the StreetMapper Mobile LIDAR Mapping, in "Real World” Projectes, Stuttgard. PhotogrammetricWeek '07, 215-225. Available from Internet: http://www.ifp.uni-stuttgart.de/publications/phowo07/index.en.html 